\title{
Endothelial Glycocalyx Integrity Is Preserved in Young, Healthy Men During a Single Bout of Strenuous Physical Exercise
}

\author{
J. MAJERCZAK ${ }^{1}$, K. DUDA ${ }^{2}$, S. CHLOPICKI ${ }^{3,4}$, G. BARTOSZ ${ }^{5}$, A. ZAKRZEWSKA ${ }^{3}$, \\ A. BALCERCZYK ${ }^{5}$, R. T. SMOLEŃSKI ${ }^{6}$, J. A. ZOLADZ $^{1}$ \\ ${ }^{1}$ Department of Muscle Physiology, Chair of Physiology and Biochemistry, Faculty \\ of Rehabilitation, University School of Physical Education, Kraków, Poland, ${ }^{2}$ Department \\ of Oncological Surgery, Center of Oncology, M. Sklodowska-Curie Memorial Institute, Kraków, \\ Poland, ${ }^{3}$ Jagiellonian Center for Experimental Therapeutics (JCET), Jagiellonian University, \\ Kraków, Poland, ${ }^{4}$ Chair of Pharmacology, Jagiellonian University Medical College, Kraków, \\ Poland, ${ }^{5}$ Department of Molecular Biophysics, University of Łódź, Łódź, Poland, ${ }^{6}$ Department \\ of Biochemistry, Medical University of Gdańsk, Gdańsk, Poland
}

Received April 2, 2015

Accepted June 12, 2015

On-line October 8, 2015

\section{Summary}

In the present study we aimed to evaluate whether oxidative stress and inflammation induced by strenuous exercise affect glycocalyx integrity and endothelial function. Twenty one young, untrained healthy men performed a maximal incremental cycling exercise - until exhaustion. Markers of glycocalyx shedding (syndecan-1, heparan sulfate and hyaluronic acid), endothelial status (nitric oxide and prostacyclin metabolites - nitrate, nitrite, 6-keto-prostaglandin $F_{1 a}$ ), oxidative stress (8-oxo-2'deoxyguanosine) and antioxidant capacity (uric acid, nonenzymatic antioxidant capacity) as well as markers of inflammation (sVCAM-1 and SICAM-1) were analyzed in venous blood samples taken at rest and at the end of exercise. The applied strenuous exercise caused a 5 -fold increase in plasma lactate and hypoxanthine concentrations $(p<0.001)$, a fall in plasma uric acid concentration and non-enzymatic antioxidant capacity $\left(p<10^{-4}\right)$, accompanied by an increase $(p=0.003)$ in sVCAM-1 concentration. Plasma 6-keto-prostaglandin $F_{10}$ concentration increased $(p=0.006)$ at exhaustion, while nitrate and nitrite concentrations were not affected. Surprisingly, no significant changes in serum syndecan-1 and heparan sulfate concentrations were observed. We have concluded, that a single bout of severe-intensity exercise is well accommodated by endothelium in young, healthy men as it neither results in evident glycocalyx disruption nor in the impairment of nitric oxide and prostacyclin production.

\section{Key words}

Endothelium • Exercise • Glycocalyx • Inflammation • Oxidative stress

\section{Corresponding author}

J. A. Zoladz, Department of Muscle Physiology, Chair of Physiology and Biochemistry, Faculty of Rehabilitation, University School of Physical Education, Al. Jana Pawla II 78, 31-571 Kraków, Poland. Fax: +48 126831316 .

E-mail: jerzy.zoladz@awf.krakow.pl

\section{Introduction}

It is generally accepted that regular physical exercise of moderate intensity enhances health status in humans (Matheson et al. 2011, Walker et al. 2014). In the recent years special attention has been given to the effect of regular physical activity on the cardiac and vascular protection (Seals et al. 2009, Walker et al. 2014). An important role in this process seems to play the exercise-induced increase in shear stress, i.e. the frictional force along endothelial cell membranes exerted by blood flow (Laughlin et al. 2008, Seals et al. 2009).

Endothelial nitric oxide synthase (eNOS)derived nitric oxide (NO) is a key factor mediating acute and sustained cardiovascular protective effects of 
exercise (Laughlin et al. 2008). Namely, it has been demonstrated that $\mathrm{NO}$ is responsible not only for vasodilation effect, but also inhibits activity of proinflammatory factors (cytokines, adhesion molecules) and participates in redox signaling (Hare and Stamler 2005). Other studies indicated that a regular physical activity, leading to an increase in laminar shear stress during exercise, increases the expression of eNOS and its phosphorylation (Hambrecht et al. 2003) resulting in an enhancement in systemic NO bioavailability (Green et al. 2004). Moreover, nitrate supplementation showed to be effective in enhancement of exercise tolerance in healthy people and in athletes (for review see Jones 2014). The training-induced changes in NO bioavailability common with an increase in antioxidant capacity (Gomez-Cabrera et al. 2008), which result in an attenuation of $\mathrm{NO}$ degradation by free radicals, leads to an anti-atherogenic phenotype of the endothelium and vascular wall (Laughlin et al. 2008). Accordingly, a number of recent studies showed that regular moderate intensity training enhances cardiovascular health status in humans (Walker et al. 2014, Seals et al. 2009). Moreover, there is growing body of evidence that exercise-based rehabilitation, individually prescribed, provides considerable protection in the primary and secondary prevention of coronary heart disease and improves quality of life of patient with cardiovascular disease (Swift et al. 2013).

On the other hand, a single bout of strenuous exercise especially when performed by previously untrained subjects enhances cardiovascular risk, as reported in the cross-sectional and retrospective study (Albert et al. 2000). Accordingly, it could well be that despite the fact that regular low and moderate intensity physical activity is indeed associated with reduced longterm morbidity and mortality, an acute challenging exercise can transiently increase the risk of fatal or nonfatal cardiovascular events (Dangardt et al. 2013) possibly via maladaptive endothelial response. In fact, an impairment of flow-mediated dilation response after heavy exercise intensity $\left(>80 \% V_{2 \max }\right)$ has been clearly demonstrated in healthy humans (Dawson et al. 2013). Still relatively little is known concerning the mechanism(s) by which single bout of strenuous exercise develops harmful effects on endothelial cells (Dawson et al. 2013).

Even less is known concerning the effect of a single bout of a strenuous exercise on the glycocalyx a key structure for adequate endothelial function (Florian et al. 2003, Reitsma et al. 2007). Glycocalyx is a thin carbohydrate-rich gel-like layer $(\sim 0.1 \mu \mathrm{m}$ in capillaries) negatively charged, covering endothelial cells, which constitutes a part of blood-to-tissue permeability barrier and plays various other functions. In fact, the endothelial glycocalyx not only prevents transvascular protein leakage, but also reduces leukocyte adhesion and participates in the mechanotransduction, i.e. transmits mechanical forces induced by blood flow into biochemical signals (Reitsma et al. 2007).

Number of reports suggested that glycocalyx damage might be the earliest stage of the alterations of endothelial function that not only precedes but also promotes the development of endothelial dysfunction (Reitsma et al. 2007, Annecke et al. 2011). Interestingly, in cultured endothelial cells, degradation of glycocalyx by heparinase, which specifically break down heparan sulfate glycosaminoglycan, impairs NO production by endothelial cells suggesting a close link between glycocalyx integrity and NO bioavailability (Florian et al. 2003). Furthermore, the glycocalyx might be damaged by the well-known pathological condition inducing endothelial dysfunction such as reactive oxygen species (ROS), inflammation, oxidized lipoproteins (Reitsma et al. 2007), and some of them are known to constitute the physiological response to exercise.

To our best knowledge, no data has been reported so far concerning the effect of single bout of strenuous exercise undertaken by untrained, healthy people on the endothelial glycocalyx integrity. Therefore, we have hypothesized that a single bout of strenuous exercise, which requires to reach maximal oxygen uptake $\left(\mathrm{VO}_{2 \max }\right)$, in young, healthy, but previously untrained men will be accompanied by glycocalyx degradation and this damage will be related to the exercise-induced increase in oxidative stress and inflammation. The question regarding the effect of a single bout of strenuous exercise on glycocalyx seems to be especially relevant, since currently a maximal exercise tests are routinely performed in untrained subjects in order to assess their $\mathrm{VO}_{2 \max }$ (Wasserman et al. 2005).

\section{Methods}

\section{Subjects}

Twenty one young, healthy, non-smoking men (mean \pm SE: age $22.7 \pm 0.3$ years; body mass $74.9 \pm 2.9 \mathrm{~kg}$; height $179 \pm 1 \mathrm{~cm}$; BMI $23.3 \pm 0.7 \mathrm{~kg} \cdot \mathrm{m}^{-2}$ ) with moderate 
level of physical fitness $\left(\mathrm{VO}_{2 \max }\right.$ amounting to about $43.9 \pm 1.0 \mathrm{ml} \cdot \mathrm{min}^{-1} \cdot \mathrm{kg}^{-1}$ ) participated in this study. The subjects had no previous experience with maximal incremental exercise tests. Subjects were asked to avoid heavy exercise the day before and on the day of the test as well as to avoid caffeinated and alcoholic beverages $24 \mathrm{~h}$ before exercise. The subjects provided written informed consent to participate in the study. The study was conducted with permission of the Ethical Committee (Commission for Bioethics at the Regional Medical Chamber in Krakow, opinion No 48/KBL/OIL/2009) according to principles established in the Declaration of Helsinki for research on human subjects.

\section{Exercise protocol}

An incremental exercise (IT) was performed on the cycloergometer Ergo-Line GmbH \& Co KG 800s (Bitz, Germany) following a 6 min resting period allowed to establish basic cardio-respiratory parameters. The exercise test was performed at pedaling rates of $60 \mathrm{rev} \cdot \mathrm{min}^{-1}$ starting from power output $30 \mathrm{~W}$ and followed by gradual increase by $30 \mathrm{~W}$ every 3 min until exhaustion (Zoladz et al. 1995). Based on our previous experience (Zoladz et al. 1995, Majerczak et al. 2008, 2014) reaching maximal power output $\left(\mathrm{PO}_{\max }\right)$ during this exercise protocol requires to reach $\mathrm{VO}_{2 \max }$.

Exercise test was performed about $2 \mathrm{~h}$ after an intake of light meal ( $\sim 500 \mathrm{kcal})$ composed of $\sim 55 \%$ of carbohydrates, $\sim 25 \%$ of fat and $\sim 20 \%$ of protein in order to avoid hypoglycemic events.

\section{Heart rate (HR)}

The heart rate in this study was monitored using a heart rate monitor (Polar S810, Polar Electro Oy, Kempele, Finland).

\section{Blood sampling}

Blood samples were taken from an antecubital vein at two time points: (a) at rest in the fasting state and (b) in the final stage of the maximal incremental exercise test lasting about $25 \mathrm{~min}$, which started at about $2 \mathrm{~h}$ after a light meal, i.e. the second blood sample was taken at about $2.5 \mathrm{~h}$ after a light meal. Blood for parameters analyzed in plasma (except lactate, see below) was collected in plain tubes containing EDTA and then centrifuged at $653 \times \mathrm{g}$ for $15 \mathrm{~min}$ in $4{ }^{\circ} \mathrm{C}$. Plasma samples were stored at $-80{ }^{\circ} \mathrm{C}$ until analysis. Blood for parameters analyzed in serum was collected into plain tubes with clotting activator and left to clot for a minimum of $30 \mathrm{~min}$ at room temperature and then centrifuged at $1469 \times g$ for $10 \mathrm{~min}$ in $4{ }^{\circ} \mathrm{C}$. Serum was stored at $-80^{\circ} \mathrm{C}$ until analysis.

\section{Plasma lactate concentration}

Blood samples were transferred to $1.8 \mathrm{ml}$ Eppendorf tubes containing $1 \mathrm{mg}$ ammonium oxalate and $5 \mathrm{mg}$ sodium fluoride, mixed for about $20 \mathrm{~s}$ and centrifuged at $1055 \times \mathrm{g}$ for $4 \mathrm{~min}$. The supernatants containing blood plasma (about $0.2 \mathrm{ml}$ ) were stored at $-40{ }^{\circ} \mathrm{C}$ until further analysis of plasma lactate concentration $\left[\mathrm{La}^{-}\right]_{\mathrm{pl}}$ (Vitros 250 Dry Chemistry System; Kodak, Rochester, NY, USA).

\section{Plasma hypoxanthine and uric acid concentrations}

Plasma hypoxanthine $[\mathrm{Hx}]_{\mathrm{pl}}$ and uric acid concentrations $[\mathrm{UA}]_{\mathrm{pl}}$ were evaluated according to previously described reversed-phase high performance liquid chromatography (HPLC) procedure (Smolenski and Yacoub 1993).

\section{Plasma 6-keto-PGF $F_{\text {Id }}$ concentration}

The concentration of 6-keto- $\mathrm{PGF}_{1 \alpha}$ in plasma was assayed using commercially available colorimetric competitive enzyme immunoassay kits (ADI-900-004, Assay Design / Enzo Life Sciences). Multi-Mode Microplate Reader (BioTek, Winooski, VT, USA) was used to measure absorbance at $405 \mathrm{~nm}$.

\section{Plasma nitrite $\left(\mathrm{NO}_{2}^{-}\right)$and nitrate $\left(\mathrm{NO}_{3}^{-}\right)$concentration}

The nitrate and nitrite concentration in plasma was measured by sensitive high-pressure liquid chromatography techniques (ENO-20 $\mathrm{NO}_{\mathrm{x}}$ Analyzer; EiCom, Kyoto, Japan).

\section{Serum heparan sulfate and syndecan-1 concentrations}

Heparan sulfate was measured after pretreatment of serum with actinase E (Sigma-Aldrich, St. Louis, MO, USA). Serum heparan sulfate concentration $[\mathrm{HS}]_{\mathrm{s}}$ was evaluated with special ELISA kit (Seikagaku Corp., Tokyo, Japan). Syndecan-1 concentration [Syndecan-1 $]_{\mathrm{s}}$ was determined in serum using human Syndecan-1 ELISA Kit (Diaclone CD138, No 950.640.096, Diaclone Research, Besancon, France). Both tests were conducted according to manufacturer's instructions. Intensity of the colorful reaction was estimated in optical density (OD) using the microplate reader BioTek ELx808 (BioTek Instruments, Winooski, VT, USA) at $450 \mathrm{~nm}$. 


\section{Serum hyaluronic acid concentration}

Hyaluronic acid concentration $[\mathrm{HA}]_{\mathrm{s}}$ was determined using Corgenix, Inc., Broomfield, Colorado, USA according to manufacturer's instructions. MultiMode Microplate Reader (BioTek, Winooski, VT, USA) was used to measure OD at $450 \mathrm{~nm}$.

\section{Serum VCAM-1 and ICAM-1 concentrations}

Serum soluble Vascular Cell Adhesion Molecule [sVCAM-1 $]_{\mathrm{s}}$ and soluble Intercellular Adhesion Molecule1 [sICAM-1 $]_{\mathrm{s}}$ concentrations were evaluated with special ELISA kit (Human sVCAM-1, \#KHT0602/KHT0601, ELISA Kit, Invitrogen and Human sICAM-1, \#KHS5411, ELISA Kit, Invitrogen) according to manufacturer's instructions. Intensity of the colorful reaction was estimated by optical density using a spectrophotometer MINI-BOS; Biomedica, Italy (at $450 \mathrm{~nm}$ ).

\section{Plasma 8-oxo-2'-deoxyguanosine concentration}

Plasma 8-oxo-2'-deoxyguanosine concentration [8-oxo-dG $]_{\mathrm{pl}}$ was estimated using Cayman Chemical, ELISA Kit $\left(\mathrm{N}^{\circ} 589320\right)$ developed for the measurement of DNA/RNA oxidative damage, according to the manufacturer's instruction. The absorbance was measured at a wavelength $405 \mathrm{~nm}$ using microplate reader (BioTek $\AA$, Winooski, VT, USA). Before the final estimation of the 8-oxo-dG level in the plasma, we have tested the dilution of the plasma samples. Two samples of each group were taken and diluted 25-, 50-, and 100-times, based on the manufacturer's instruction. For the final assay, 50-times dilution was chosen. The 8-oxo-dG level was calculated based on the standard cure, performed every time on the each tested plate, according to the protocol attached to the kit.

\section{Estimation of Non-Enzymatic Antioxidant Capacity}

Non-Enzymatic Antioxidant Capacity (NEAC) of blood plasma was estimated by $\mathrm{ABTS}^{\bullet+}$ decolorization method (Re et al. 1999) modified for a microplate reader.

\section{Estimation of maximal heart rate $\left(H R_{\max }\right)$}

Maximal heart rate $\left(\mathrm{HR}_{\max }\right)$ was predicted for each subject from the formula developed by Tanaka $e t$ al. (2001).

$$
\mathrm{HR}_{\max }=208-0.7 \cdot \text { age } \quad(\mathrm{r}=-0.90) \quad(\text { equation } 1)
$$

Estimation of maximal oxygen uptake $\left(\mathrm{VO}_{2 \max }\right)$

The estimation of the $\mathrm{VO}_{2 \max }$ in this study was performed based on a linear relationship between maximal power output $\left(\mathrm{PO}_{\max }\right)$ reached during maximal incremental exercise test and the measured $\mathrm{VO}_{2 \max }$, established during the same exercise protocol for the group of young, healthy subjects $(\mathrm{n}=38)$ (Majerczak et al. 2014). Namely, the $\mathrm{VO}_{2 \max }\left(\mathrm{ml} \cdot \mathrm{min}^{-1}\right)$ in the present study was estimated based on the $\mathrm{PO}_{\max }$ (expressed in Watts), reached during the maximal incremental exercise test, using the following formula:

$\mathrm{VO}_{2 \max }=1307+8.43 \cdot \mathrm{PO}_{\text {max }} \quad\left(\mathrm{r}=0.84, \mathrm{p}<10^{-4}\right)$

(equation 2)

\section{Plasma volume change during exercise $(\triangle P V)$}

Plasma volume change during exercise was calculated for each subject based on the hematocrit level using Van Beaumont' equation (Van Beaumont 1972). Then the concentration of blood parameters measured at exhaustion were recalculated using the formula presented by Berthoin et al. (2002). In Table 1 we have presented raw data (value measured at $\mathrm{PO}_{\max }$ ) and also data after recalculation for the changes in plasma volume during incremental exercise (value corrected).

\section{Statistics}

The results are expressed as means and standard error (SE). The statistical significance of differences for paired samples was tested using the non-parametric Wilcoxon test and non-asymptotic, exact, two-sided $\mathrm{p}$-values are presented. Significance was set at $\mathrm{p}<0.05$. The statistics was done using the statistical packet STATISTICA 10.0 (StatSoft, Tulsa, OK, USA) and StatXact 9.0 (Cytel Software Corporation, Cambridge, MA, USA).

\section{Results}

Power output reached at exhaustion, estimated maximal oxygen uptake and estimated maximal heart rate

The incremental cycling exercise performed by our subjects lasted for $23 \pm 0.7 \mathrm{~min}$. The heart rate at the exhaustion $\left(\mathrm{HR}_{\max }\right)$ has amounted to $188 \pm 2$ beats per minute and it constituted $98 \%$ of age-predicted $\mathrm{HR}_{\max }$ (see equation 1) for this group of subjects.

The power output reached at the end of maximal incremental cycling exercise $\left(\mathrm{PO}_{\max }\right)$ has amounted to $229 \pm 7 \mathrm{~W}$. The estimated $\mathrm{VO}_{2 \max }\left(\right.$ at $\mathrm{PO}_{\max }$, see equation 2) for the entire group of subjects $(n=21)$ has amounted to $3237 \pm 60 \mathrm{ml} \cdot \mathrm{min}^{-1}$, i.e. $43.9 \pm 1.0 \mathrm{ml} \cdot \mathrm{min}^{-1} \cdot \mathrm{kg}^{-1}$. 
Table 1. Selected biochemical blood variables measured at rest in fasted state (basal) and at the end of the maximal incremental test $\left(\right.$ at $\mathrm{PO}_{\max }$.

\begin{tabular}{|c|c|c|c|}
\hline & Basal value & $\begin{array}{c}\text { Value at POmax } \\
\text { measured }\end{array}$ & $\begin{array}{c}\text { Value at POmax } \\
\text { corrected }\end{array}$ \\
\hline$\left[\right.$ Syndecan-1] $\left(n g \cdot m l^{-1}\right)$ & $39.5 \pm 3.4$ & $47.2 \pm 3.6$ & $41.3 \pm 3.7$ \\
\hline$[H S]_{s}\left(\mu g \cdot m l^{-1}\right)$ & $4.91 \pm 1.09$ & $5.38 \pm 1.27$ & $4.73 \pm 1.13$ \\
\hline$[H A]_{s}\left(n g \cdot m l^{-1}\right)$ & $40.4 \pm 3.5$ & $25.2 \pm 2.4 * *$ & $22.2 \pm 2.1 * * *$ \\
\hline$\left[6-k e t o-P G F_{l o}\right]_{p l}\left(p g \cdot \mathrm{ml}^{-1}\right)$ & $179 \pm 26$ & $256 \pm 33 * *$ & $223 \pm 28 * *$ \\
\hline$\left[\mathrm{NO}_{2}^{-}\right]_{\mathrm{pl}}\left(\mu \mathrm{mol} \cdot l^{-1}\right)$ & $0.56 \pm 0.09$ & $0.61 \pm 0.09$ & $0.53 \pm 0.08$ \\
\hline$\left[\mathrm{NO}_{3}^{-}\right]_{p l}\left(\mu \mathrm{mol} \cdot l^{-1}\right)$ & $26.5 \pm 1.9$ & $31.1 \pm 2.2$ & $27.5 \pm 2.0$ \\
\hline$\left[\mathrm{NO}_{2}^{-}\right]_{p l}+\left[\mathrm{NO}_{3}^{-}\right]_{p l}\left(\mu \mathrm{mol} \cdot l^{-l}\right)$ & $27.04 \pm 1.8$ & $31.7 \pm 2.3$ & $28.1 \pm 2.0$ \\
\hline$[s V C A M-1]_{s}\left(n g \cdot m l^{-1}\right)$ & $702 \pm 46$ & $913 \pm 70 * * *$ & $802 \pm 63 * *$ \\
\hline$[\operatorname{sICAM}-1]_{s}\left(n g \cdot m l^{-1}\right)$ & $217 \pm 10$ & $243 \pm 9 * * *$ & $213 \pm 8$ \\
\hline$[8-o x o-d G]_{p l}\left(p g \cdot m l^{-1}\right)$ & $5427 \pm 389$ & $6190 \pm 311 * *$ & $5433 \pm 294$ \\
\hline NEAC (Trolox Equivalents) & $1467 \pm 25$ & $1437 \pm 18^{* *}$ & $1258 \pm 18^{* * *}$ \\
\hline$[U A]_{p l}\left(\mu \mathrm{mol} \cdot l^{-1}\right)$ & $204 \pm 7$ & $201 \pm 7$ & $180 \pm 7.4 * * *$ \\
\hline$[\mathrm{Hx}]_{\mathrm{pl}}\left(\mu \mathrm{mol} \cdot \mathrm{l}^{-1}\right)$ & $0.006 \pm 0.001$ & $0.032 \pm 0.003 * * *$ & $0.028 \pm 0.003 * * *$ \\
\hline$\left[\mathrm{La}^{-}\right]_{\mathrm{pl}}\left(\mathrm{mmol} \cdot \mathrm{l}^{-1}\right)$ & $1.5 \pm 0.2$ & $8.0 \pm 0.5 * * *$ & $7.0 \pm 0.4^{* * *}$ \\
\hline
\end{tabular}

Values presented as means \pm SE. Non asymptotic, exact, 2 -sided $p$-values are presented. $* p<0.05, * * p<0.01, * * * p<0.001$. Values at $\mathrm{PO}_{\max }$ are presented as measured and as corrected for exercise-induced plasma volume change $(\Delta \mathrm{PV})$. [Syndecan-1] $]_{\mathrm{s}}$ (serum syndecan-1 concentration), $[\mathrm{HS}]_{\mathrm{s}}$ (serum heparan sulfate concentration), $[\mathrm{HA}]_{\mathrm{s}}$ (serum hyaluronic acid concentration), $\left[6-\mathrm{keto} \mathrm{PGF}_{1 \mathrm{a}}\right]_{\mathrm{pl}}$ (plasma 6-keto-prostaglandin $\mathrm{F}_{1 \mathrm{a}}$ concentration), $\left[\mathrm{NO}_{2}^{-}\right]_{\mathrm{pl}}$ (plasma nitrite concentration), $\left[\mathrm{NO}_{3}{ }^{-}\right]_{\mathrm{pl}}$ (plasma nitrate concentration), $\left[\mathrm{NO}_{2}{ }^{-}\right]_{\mathrm{pl}}$ $+\left[\mathrm{NO}_{3}{ }^{-}\right]_{\mathrm{pl}}$ (sum of plasma nitrite and nitrate), [sVCAM-1 $]_{\mathrm{s}}$ (serum soluble vascular cell adhesion molecule-1), [sICAM-1 $]_{\mathrm{s}}$ (serum soluble intercellular adhesion molecule-1), [8-oxo-dG $]_{\mathrm{pl}}$ (plasma 8-oxo-2'-deoxyguanosine concentration), NEAC (non-enzymatic antioxidant capacity), $[\mathrm{UA}]_{\mathrm{pl}}$ (plasma uric acid concentration), $[\mathrm{Hx}]_{\mathrm{pl}}$ (plasma hypoxanthine concentration), $\left[\mathrm{La}^{-}\right]_{\mathrm{pl}}$ (plasma lactate concentration).

A

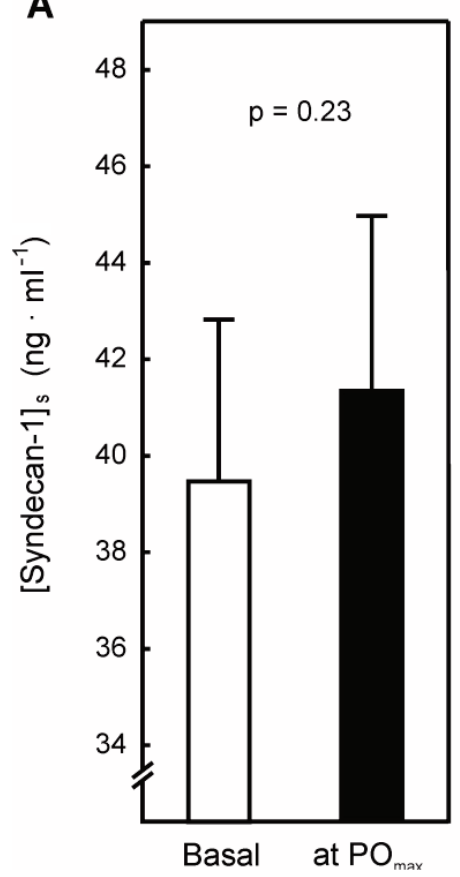

B

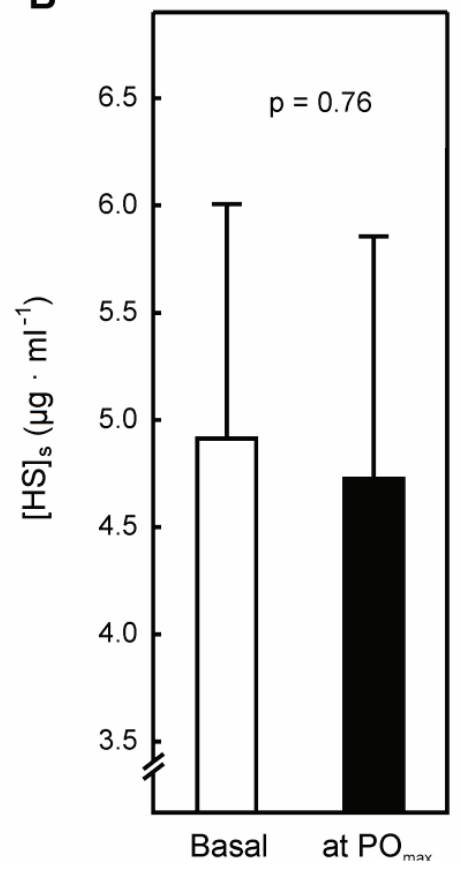

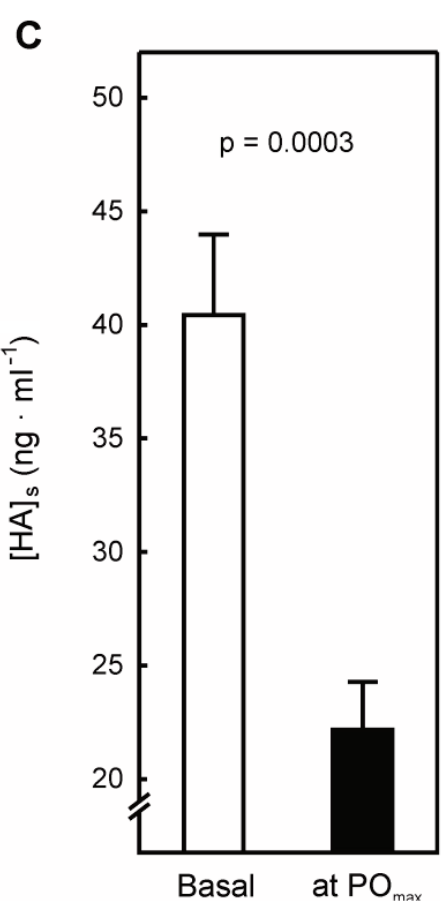

Fig. 1. Markers of glycocalyx shedding during strenuous exercise. Serum syndecan-1 concentration at rest (basal) and at exhaustion (panel A), serum heparan sulfate concentration $\left([\mathrm{HS}]_{s}\right.$ ) at rest (basal) and at exhaustion (panel B) as well as serum hyaluronic acid concentration $\left([\mathrm{HA}]_{s}\right)$ at rest (basal) and at exhaustion (panel C). Values presented as means $\pm \mathrm{SE}$. 
Plasma lactate and hypoxanthine concentration

Single bout of strenuous exercise incremental exercise resulted in a decrease in plasma volume (PV) amounting to $14.2 \pm 1.4 \%$. The incremental exercise performed in the studied group of subjects was accompanied by a $\sim 5$-fold increase $\left(\mathrm{p}<10^{-4}\right)$ in plasma lactate and in plasma hypoxanthine concentrations (Table 1).

Serum syndecan-1, heparan sulfate and hyaluronic acid concentrations

No significant changes in serum syndecan-1 (Fig. 1A, $p=0.23$ ) and serum heparan sulfate concentrations after strenuous exercise were observed (Fig. $1 \mathrm{~B}, \mathrm{p}=0.76$ ). A significantly lower serum hyaluronic acid concentration at exhaustion was found when compared to its basal value (by $\sim 34 \%$, Fig. $1 \mathrm{C}, \mathrm{p}=0.0003$ ).
Plasma nitrite, nitrate and 6-keto-prostaglandin $F_{1 \alpha}$ concentrations

No significant changes $(p>0.05)$ in plasma nitrite $\left[\mathrm{NO}_{2}{ }^{-}\right]_{\mathrm{pl}}$, nitrate $\left(\left[\mathrm{NO}_{3}{ }^{-}\right]_{\mathrm{pl}}\right.$, and sum of plasma nitrite and nitrate concentrations after exercise were found when compared to their levels at rest (Table 1). In contrast, a significant increase (by $\sim 70 \%$ ) in plasma 6-keto-PGF ${ }_{1 \alpha}$ concentration after strenuous exercise has been presented $(\mathrm{p}=0.006$, Table 1$)$.

Serum soluble VCAM-1 and soluble ICAM-1 concentrations

A significant but small increase in [sVCAM-1] by $\sim 17 \%$ has been observed ( $\mathrm{p}=0.003$, Fig. $2 \mathrm{~A}$ ) after exercise. No significant changes in [sICAM-1 $]_{\mathrm{s}}$ during exercise was noticed ( $p=0.65$, Fig. $2 B$ ).
A

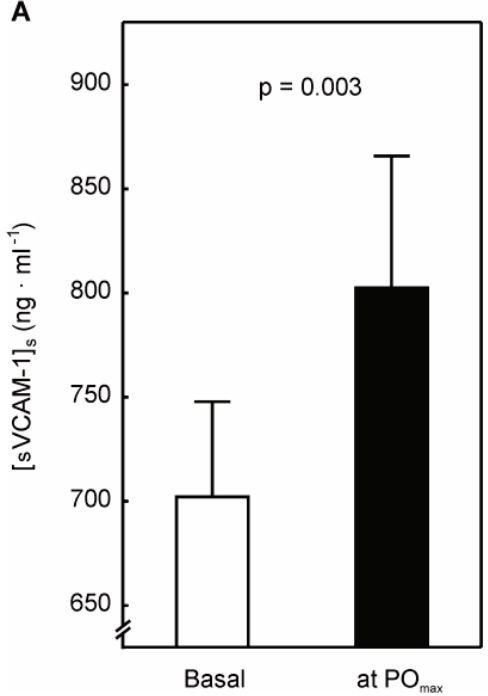

A

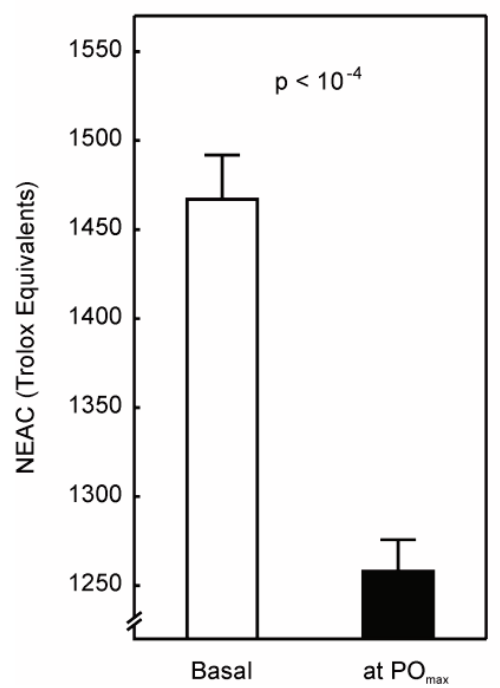

B

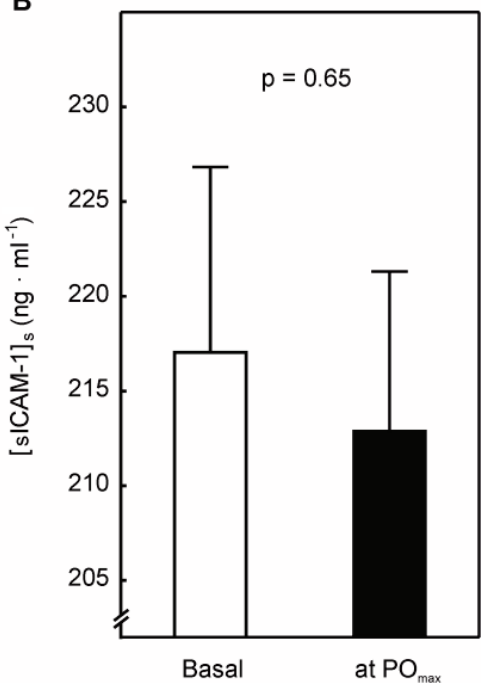

B

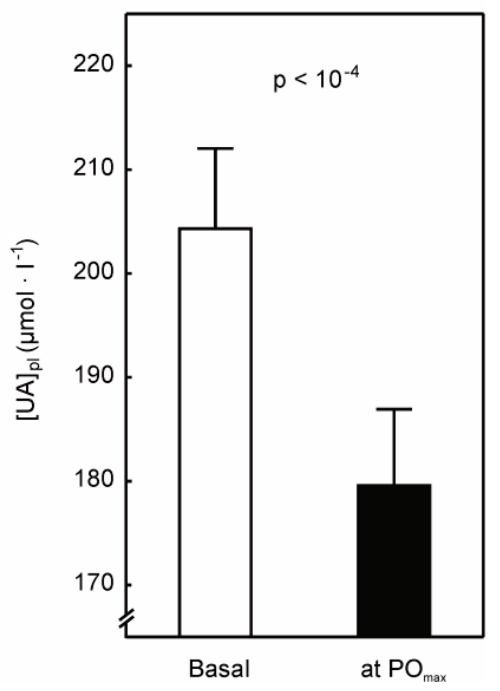

Fig. 2. Markers of inflammation during strenuous exercise. Serum soluble vascular adhesion molecule-1 concentration ([SVCAM- 1$]_{s}$ ) at rest (basal) and at exhaustion (panel A) and serum soluble intracellular adhesion molecule-1 concentration $\left([\text { sICAM-1 }]_{s}\right)$ at rest (basal) and at exhaustion (panel B). Values presented as means $\pm \mathrm{SE}$.

Fig. 3. Antioxidant capacity during strenuous exercise. Plasma nonenzymatic antioxidant capacity $\left([N E A C]_{\mathrm{pl}}\right)$ at rest (basal) and at exhaustion (panel A) and plasma uric acid concentration ([UA $]_{\mathrm{pl}}$ ) at rest (basal) and at exhaustion (panel B). Values presented as means $\pm \mathrm{SE}$. 
Plasma 8-oxo-2'-deoxyguanosine concentration, nonenzymatic antioxidant capacity and uric acid concentration

No significant changes in $[8-\mathrm{oxo}-\mathrm{dG}]_{\mathrm{pl}}(\mathrm{p}=0.75)$ during strenuous incremental cycling exercise was noticed (Table 1), however, a significant decrease (by $\sim 14 \%$, Fig. $3 \mathrm{~A}, \mathrm{p}<10^{-4}$ ) in plasma NEAC accompanied by a significant decrease in plasma uric acid concentration (by $\sim 12 \%$, Fig. $3 \mathrm{~B}, \mathrm{p}<10^{-4}$ ) after this strenuous exercise was found.

\section{Discussion}

The main and original finding of the present study is that a single bout of metabolically highly demanding exercise leading to a mild endothelial inflammatory response (Fig. 2A) and attenuation of antioxidant defense (Fig. 3), appears to have no harmful effect on the endothelial glycocalyx integrity (Fig. 1) and did not impair endothelial function in young, healthy men (Table 1) with normal $\mathrm{VO}_{2 \max }$ (amounting to about $43.9 \pm 1.0 \mathrm{ml} \cdot \mathrm{min}^{-1} \cdot \mathrm{kg}^{-1}$ ).

\section{Exercise-induced metabolic stress}

In the present study we have used a maximal incremental cycling exercise lasting about 25-30 min, as an exercise model. Such exercise protocols are frequently used to assess human physical capacity, including $\mathrm{VO}_{2 \max }$ considered as the main physiological indicator of aerobic capacity (Åstrand and Rodahl 1986, Wasserman et al. 2005). In its final stage this fatiguing exercise requires to reach $\mathrm{HR}_{\max }, \mathrm{VO}_{2 \max }$ (Zoladz et al. 1995, Majerczak et al. 2008, 2014) and presumably the maximal cardiac output (Åstrand and Rodahl 1986), therefore it generates the highest challenge to cardiovascular system (Åstrand and Rodahl 1986, Wasserman et al. 2005, Zoladz et al. 2015). In the present study, heart rate reached by subjects at the end of incremental exercise has amounted to $188 \pm$ 2 beats $\cdot \min ^{-1}\left(\sim 98 \%\right.$ of age predicted $\left.H_{\max }\right)$. Moreover, we have found a pronounced increase in plasma lactate concentration from $1.5 \pm 0.2 \mathrm{mmol} \cdot 1^{-1}$ at rest to $7.0 \pm 0.4 \mathrm{mmol} \cdot \mathrm{l}^{-1}$ at fatigue, indicating a high contribution of anaerobic glycolysis to ATP resynthesis in the final stage of this exercise protocol. We have also found a 5-fold increase in plasma hypoxanthine concentration at fatigue, considered as an important marker of energetic state of muscle, showing the magnitude of adenine nucleotide degradation during exercise (Sahlin et al. 1991). In general, in the present study we have used rather demanding mode of exercise, that requires to reach $\mathrm{VO}_{2 \max }$, therefore generating a maximal challenge to the circulatory system in humans.

\section{Strenuous exercise and the markers of glycocalyx damage}

It has been reported that an acute high intensity exercise is accompanied by a transient endothelial dysfunction (a decrease in flow-mediated vasodilation response) (Dawson et al. 2013), however the knowledge concerning the effect of strenuous exercise on glycocalyx in humans is limited. Nevertheless, it has been reported in an animal model that chronic electrical stimulation of skeletal muscles, which mimics muscle contraction, is accompanied by an disruption of glycocalyx, which as suggested by authors is needed to induce muscle capillarization (Brown et al. 1996). Moreover, it is known that high concentration of catecholamines in trauma patients, becomes maladaptive and contributes to the glycocalyx damage as well as to endothelial dysfunction (Johansson et al. 2011). Therefore, one would expect that a single bout of high intensity exercise, which requires to reach $\sim 100 \%$ of $\mathrm{VO}_{2 \max }$, leading to a marked increase in plasma catecholamine concentration (Galbo 1983) and to an increase in oxidative stress (Powers and Jackson 2008) as well as inflammatory response (Ostrowski et al. 1999) might have a harmful impact on the glycocalyx layer in young, untrained men. However, in the present study, we have found no harmful effect of this stressful exercise on the glycocalyx, as judged by no changes in serum syndecan-1 and serum heparan sulfate concentrations (Fig. 1). Surprisingly, in the present study, instead of an expected increase in the plasma hyaluronic acid concentration (a marker of glycocalyx damage), we have observed a significant decrease in hyaluronic acid plasma concentration during this strenuous exercise (Fig. 1C). Although we have no direct explanation for this phenomena there are number of possible reasons for this unexpected response. One might speculate that decrease in hyaluronic acid concentration was due to an exerciseinduced oxidative stress (Hrabarova et al. 2011) or exercise-induced shear stress enhancing hyaluronic acid incorporation into glycocalyx (Gouverneur et al. 2006). Unfortunately, no data concerning hyaluronan incorporation to glycocalyx during exercise has been presented so far. One should also take into account that a decrease in hyaluronic acid concentration during exhaustive exercise might be related to the activation of scavenger activity of liver sinusoidal endothelial cells (LSEC) known to uptake hyaluronic acid (Smedstød 
1991). On the other hand, it has been reported that during heavy intensity exercise liver blood flow is diminished by $\sim 50 \%$ when compared to its resting value (Bergeron et al. 2001) hence the observed decrease in HA concentration at exhaustion cannot be simply explained by a greater clearance of HA by sinusoidal liver endothelial cells and therefore the concept of the exercise-induced activation of HA uptake by LSEC requires further studies. Another option could be increased exchange of water between intravascular and interstitial compartment during exercise that may help to selectively export hyaluronan into the extravascular space. Nevertheless, our results indicate that a single bout of strenuous exercise seem to be not harmful to the glycocalyx layer in young, healthy men, as judged by no changes in plasma serum syndecan-1 and serum heparan sulfate concentrations.

\section{Exercise-induced endothelial inflammation}

In the present study we have found a significant increase $(\mathrm{p}=0.003)$ in soluble VCAM-1 concentration (Fig. 2A) during exercise when compared to its level at rest, suggesting an activation of endothelial inflammatory response, which is in agreement with the earlier reports by Ostrowski et al. (1999). Inflammatory stimulation during exercise leads to an increase in soluble adhesion molecules (VCAM and ICAM), which regulate attachment and transendothelial migration of leukocytes (Bartzeliotou et al. 2007). Our results suggest that a strenuous exercise undertaken occasionally even in case of a young, healthy people with normal $\mathrm{VO}_{2 \max }$, may enhance endothelial inflammation, which is not accompanied however by a glycocalyx degradation.

\section{Exercise-induced oxidative stress and glycocalyx status}

It is well known, that free radicals might induce glycocalyx damage (Marechal et al. 2008) and endothelial dysfunction leading to an attenuation of NO bioavailability (Florian et al. 2003, Green et al. 2004). It is suggested, that high intensity exercise or exercise of long duration is accompanied by an appropriate increase in reactive oxygen species (ROS) and reactive nitrogen species (RNS), overwhelming the antioxidant defence (Lovlin et al. 1987). In our study, no significant difference in the plasma 8-oxo-2'-deoxyguanosine measured at exhaustion when compared to its value at rest has been found (Table 1). Despite no changes in plasma 8-oxo-dG, which is a marker of oxidative damage to nucleotides, we have found a significant exercise- induced decrease in plasma non-enzymatic antioxidant capacity (Fig. 3A), which in this study represents the slow-reacting antioxidants such as tyrosine and tryptophan (Lewinska et al. 2007). Moreover, we have observed an exercise-induced attenuation in uric acid concentration (Fig. 3B), a low-molecular mass, fast reacting-antioxidant, which constitutes one half of the antioxidant capacity of serum (Ames et al. 1981). Uric acid/urate is a product of purine metabolism and acts as a scavenger of peroxyl radicals, hydroxyl radicals and single oxygen. In skeletal muscle during intense exercise urate in reaction with free radicals is converted to allantoin (Hellsten et al. 2001, Kandár et al. 2014). Additionally, urate can be taken from blood by skeletal muscle, heart and pulmonary bed and it can act there as a scavenger (Becker 1993, Hellsten et al. 2001). A decrease in plasma urate concentration, as found in the present study (Fig. 3B), may indicate that uric acid acts indeed as a scavenger during exercise in blood but, this result might suggest that it can also be taken up by skeletal muscle during exercise. The attenuation of antioxidant defence (Fig. 3), suggesting an increase in oxidative stress, was not however accompanied by a glycocalyx damage as reflected by no changes in serum syndecan-1 and heparan sulfate concentrations (Fig. 1).

Nitric oxide and prostacyclin metabolites during exercise

It is well known, that endothelium produces and secretes number of vasoactive substances including vasodilators such as nitric oxide (NO) and prostacyclin ( $\mathrm{PGI}_{2}$ ) (Clough 2015, Zoladz et al. 2015). In the present study, similarly to an early reports by our group (Zoladz et al. 2009, 2010) we have observed a pronounced exercise-induced increase in plasma 6-keto-PGF ${ }_{1 \alpha}$ (Table 1). Surprisingly, the strenuous exercise, applied in this study, which required to reach maximal oxygen uptake (Zoladz et al. 1995, Majerczak et al. 2014) and most likely maximal cardiac output (Åstrand and Rodahl 1986) was not accompanied by changes in plasma nitrite $\left(\mathrm{NO}_{2}{ }^{-}\right)$ and nitrate $\left(\mathrm{NO}_{3}{ }^{-}\right)$concentrations (Table 1). Our results are in agreement with previous study showing no effect of moderate as well as high intensity exercise on the plasma nitrate concentration in humans (St Croix et al. 1999). Lack of the increase in NO metabolites in plasma during fatiguing maximal exercise is rather surprising in view of postulated a major role of $\mathrm{NO}$ in vasodilatation during exercise in humans (Joyner and Green 2009). However, lack of increase in nitrite/nitrate concentration after high-intensity exercise may be explained by quick 
NO inactivation in reaction with superoxide and in consequence peroxynitrite formation (Pacher et al. 2007) in the oxidative stress condition of high intensity exercise.

Altogether, our results indicate that the endothelial glycocalyx layer in young, healthy men is relatively resistant to the metabolic stress induced by strenuous exercise as judged by an increase in plasma lactate and hypoxanthine concentrations (Table 1) despite the presence of endothelial inflammatory response (Fig. 2A) and an exercise-induced decrease in antioxidant defence (Fig. 3). It should be added that no effect of oxidative stress and inflammation on glycocalyx layer might be due to the fact that in our experiment the exposition to oxidative stress and inflammation was rather short, since this exercise test lasted about $25 \mathrm{~min}$ and its fatiguing part (above the lactate threshold, i.e. in heavy intensity exercise domain) about $10 \mathrm{~min}$. Perhaps upon prolonged exposure to oxidative stress and inflammation or in susceptible individuals in whom endothelium represent locus minoris resistentiae glycocalyx damage could be observed. Therefore, our results cannot be simply extrapolated to the older subject or patients with various diseases accompanied by endothelial dysfunction such as hypertension, atherosclerosis, diabetes or heart failure. Nevertheless, the present study suggests that a single bout of metabolically highly demanding exercise appears to be well accommodated by endothelium as it neither results in evident glycocalyx disruption nor in the impairment of $\mathrm{NO}$ and prostacyclin production in young, healthy men. These results have an important health message, since measurements of $\mathrm{VO}_{2 \max }$ during maximal exercise tests are routinely performed in humans when determining their exercise physical capacity (Åstrand and Rodahl 1986, Wasserman et al. 2005, Majerczak et al. 2014, Zoladz et al. 2015).

In conclusions, the present study showed that a single bout of metabolically highly demanding exercise leading to a mild endothelial inflammatory response and attenuation of antioxidant defense, appears to have no harmful effect on the endothelial glycocalyx and endothelial function in young, healthy men with normal physical capacity. This shows that the endothelial glycocalyx in young, healthy men is relativelly well protected against challenges induced by a single bout of exercise which requries reaching maximal oxygen uptake.

\section{Conflict of Interest}

There is no conflict of interest.

\section{Acknowledgements}

We would like to thank the subjects who volunteered for this study. This work was supported by the European Union from the resources of the European Regional Development Fund under the Innovative Economy Programme (grant coordinated by JCET-UJ, No. POIG.01.01.02-00-069/09).

\section{References}

ALBERT CM, MITTLEMAN MA, CHAE CU, LEE IM, HENNEKENS CH, MANSON JE: Triggering of sudden death from cardiac causes by vigorous exertion. $N$ Engl J Med 343: 1355-1361, 2000.

AMES BN, CATHCART R, SCHWIERS E, HOCHSTEIN P: Uric acid provides an antioxidant defense in humans against oxidant- and radical-caused aging and cancer: a hypothesis. Proc Natl Acad Sci USA 78: 6858-6862, 1981.

ANNECKE T, FISCHER J, HARTMANN H, TSCHOEP J, REHM M, CONZEN P, SOMMERHOFF CP, BECKER BF: Shedding of the coronary endothelial glycocalyx: effects of hypoxia/reoxygenation vs ischaemia/reperfusion. Br J Anaesth 107: 679-686, 2011.

ÅSTRAND PO, RODAHL K: Evaluation of physical performance on the basis of tests. In: Textbook of Work Physiology, Physiological Bases of Exercise. PO ÅTRAND, K RODAHL (eds), McGraw-Hill Book Company, New York, 1986, pp 354-390.

BARTZELIOTOU AI, MARGELI AP, TSIRONI M, SKENDERI K, BACOULA C, CHROUSOS GP, PAPASSOTIRIOU I: Circulating levels of adhesion molecules and markers of endothelial activation in acute inflammation induced by prolonged brisk exercise. Clin Biochem 40: 765-770, 2007.

BECKER BF: Towards the physiological function of urate. Free Radic Biol Med 14: 615-631, 1993.

BERGERON R, KJAER M. SIMONSEN L, BÜLOW J, SKOVGAARD D, GALBO H: Splanchnic blood flow and hepatic glucose production in exercising humans: role of renin-angiotensin system. Am J Physiol Regul Integr Comp Physiol 281: R1854-R1861, 2001. 
BERTHOIN S, PELAYO P, BAQUET G, MARAIS G, ALLENDER H, ROBIN H: Plasma lactate recovery from maximal exercise with correction for variations in plasma volume. J Sports Med Phys Fitness 42: 26-30, 2002.

BROWN MD, EGGINTON S, HUDLICKA O, ZHOU AL: Appearance of the capillary endothelial glycocalyx in chronically stimulated rat skeletal muscles in relation to angiogenesis. Exp Physiol 81: 1043-1046, 1996.

CLOUGH GF: Developmental conditioning of the vasculature. Compr Physiol 5: 397-438, 2015.

DANGARDT FJ, MCKENNA WJ, LÜSCHER TF, DEANFIELD JE: Exercise: friend or foe? Nat Rev Cardiol 10: 495$507,2013$.

DAWSON EA, GREEN DJ, CABLE NT, THIJSSEN DH: Effects of acute exercise on flow-mediated dilatation in healthy humans. J Appl Physiol 115: 1589-1598, 2013.

FLORIAN JA, KOSKY JR, AINSLIE K, PANG Z, DULL RO, TARBELL JM: Heparan sulfate proteoglycan is a mechanosensor on endothelial cells. Circ Res 93: e136-e142, 2003.

GALBO H: Hormonal and Metabolic Adaptation to Exercise. Thieme-Stratton Inc., New York, 1983.

GOMEZ-CABRERA MC, DOMENECH E, VIÑA J: Moderate exercise is an antioxidant: upregulation of antioxidant genes by training. Free Radic Biol Med 44: 126-131, 2008.

GOUVERNEUR M, SPAAN JA, PANNEKOEK H, FONTIJN RD, VINK H: Fluid shear stress stimulates incorporation of hyaluronan into endothelial cell glycocalyx. Am J Physiol Heart Circ Physiol 290: H458H462, 2006.

GREEN DJ, MAIORANA A, O'DRISCOLL G, TAYLOR R: Effect of exercise training on endothelium-derived nitric oxide function in humans. $J$ Physiol 561: 1-25, 2004.

HAMBRECHT R, ADAMS V, ERBS S, LINKE A, KRÄNKEL N, SHU Y, BAITHER Y, GIELEN S, THIELE H, GUMMERT JF, MOHR FW, SCHULER G: Regular physical activity improves endothelial function in patients with coronary artery disease by increasing phosphorylation of endothelial nitric oxide synthase. Circulation 107: 3152-3158, 2003.

HARE JM, STAMLER JS: NO/redox disequilibrium in the failing heart and cardiovascular system. $J$ Clin Invest 115: 509-517, 2005.

HELLSTEN Y, SVENSSON M, SJÖDIN B, SMITH S, CHRISTENSEN A, RICHTER EA, BANGSBO J: Allantoin formation and urate and glutathione exchange in human muscle during submaximal exercise. Free Radic Biol Med 31: 1313-1322, 2001.

HRABAROVA E, JURANEK I, SOLTES L: Pro-oxidative effect of peroxynitrite regarding biological systems: a special focus on high-molar-mass hyaluronan degradation. Gen Physiol Biophys 30: 223-238, 2011.

JOHANSSON PI, STENSBALLE J, RASMUSSEN LS, OSTROWSKI SR: A high admission syndecan-1 level, a marker of endothelial glycocalyx degradation, is associated with inflammation, protein C depletion, fibrinolysis, and increased mortality in trauma patients. Ann Surg 254: 194-200, 2011.

JONES AM: Influence of dietary nitrate on the physiological determinants of exercise performance: a critical review. Appl Physiol Nutr Metab 39: 1019-1028, 2014.

JOYNER MJ, GREEN DJ: Exercise protects the cardiovascular system: effects beyond traditional risk factors. $J$ Physiol 587: 5551-5558, 2009.

KANDÁR R, ŠTRAMOVÁ X, DRÁBKOVÁ P, KŘENKOVÁ J: A monitoring of allantoin, uric acid, and malondialdehyde levels in plasma and erythrocytes after ten minutes of running activity. Physiol Res 63: 753$762,2014$.

LAUGHLIN MH, NEWCOMER SC, BENDER SB: Importance of hemodynamic forces as signals for exercise-induced changes in endothelial cell phenotype. J Appl Physiol 104: 588-600, 2008.

LEWINSKA A, WNUK M, SLOTA E, BARTOSZ G: Total anti-oxidant capacity of cell culture media. Clin Exp Pharmacol Physiol 34: 781-786, 2007.

LOVLIN R, COTTLE W, PYKE I, KAVANAGH M, BELCASTRO AN: Are indices of free radical damage related to exercise intensity. Eur J Appl Physiol Occup Physiol 56: 313-316, 1987.

MAJERCZAK J, SZKUTNIK Z, DUDA K, KOMOROWSKA M, KOLODZIEJSKI L, KARASINSKI J, ZOLADZ JA: Effect of pedaling rates and myosin heavy chain composition in the vastus lateralis muscle on the power generating capability during incremental cycling in humans. Physiol Res 57: 873-884, 2008. 
MAJERCZAK J, NIECKARZ Z, KARASINSKI J, ZOLADZ JA: Myosin heavy chain composition in the vastus lateralis muscle in relation to oxygen uptake and heart rate during cycling in humans. J Physiol Pharmacol 65 : 217-227, 2014.

MARECHAL X, FAVORY R, JOULIN O, MONTAIGNE D, HASSOUN S, DECOSTER B, ZERIMECH F, NEVIERE R: Endothelial glycocalyx damage during endotoxemia coincides with microcirculatory dysfunction and vascular oxidative stress. Shock 29: 572-576, 2008.

MATHESON GO, KLÜGL M, DVORAK J, ENGEBRETSEN L, MEEUWISSE WH, SCHWELLNUS M, BLAIR SN, VAN MECHELEN W, DERMAN W, BÖRJESSON M, BENDIKSEN F, WEILER R: Responsibility of sport and exercise medicine in preventing and managing chronic disease: applying our knowledge and skill is overdue. Br J Sports Med 45: 1272-1282, 2011.

OSTROWSKI K, ROHDE T, ASP S, SCHJERLING P, PEDERSEN BK: Pro- and anti-inflammatory cytokine balance in strenuous exercise in humans. J Physiol 515: 287-291, 1999.

PACHER P, BECKMAN JS, LIAUDET L: Nitric oxide and peroxynitrite in health and disease. Physiol Rev 87: 315 424, 2007.

POWERS SK, JACKSON MJ: Exercise-induced oxidative stress: cellular mechanisms and impact on muscle force production. Physiol Rev 88: 1243-1276, 2008.

RE R, PELLEGRINI N, PROTEGGENTE A, PANNALA A, YANG M, RICE-EVANS C: Antioxidant activity applying an improved ABTS radical cation decolorization assay. Free Radic Biol Med 26: 1231-1237, 1999.

REITSMA S, SLAAF DW, VINK H, VAN ZANDVOORT MA, OUDE EGBRINK MG: The endothelial glycocalyx: composition, functions, and visualization. Pflügers Arch 454: 345-359, 2007.

SAHLIN K, EKBERG K, CIZINSKY S: Changes in plasma hypoxanthine and free radical markers during exercise in man. Acta Physiol Scand 142: 275-281, 1991.

SEALS DR, WALKER AE, PIERCE GL, LESNIEWSKI LA: Habitual exercise and vascular ageing. $J$ Physiol 587: 5541-5549, 2009.

SMEDSTØD B: Cellular events in the uptake and degradation of hyaluronan. Adv Drug Deliv Rev 7: 265-278, 1991.

SMOLENSKI RT, YACOUB MH: Liquid chromatographic evaluation of purine production in the donor human heart during transplantation. Biomed Chromatogr 7: 189-195, 1993.

ST CROIX CM, WETTER TJ, PEGELOW DF, MEYER KC, DEMPSEY JA: Assessment of nitric oxide formation during exercise. Am J Respir Crit Care Med 159: 1125-1133, 1999.

SWIFT DL, LAVIE CJ, JOHANNSEN NM, ARENA R, EARNEST CP, O'KEEFE JH, MILANI RV, BLAIR SN, CHURCH TS: Physical activity, cardiorespiratory fitness, and exercise training in primary and secondary coronary prevention. Circ J 77: 281-292, 2013.

TANAKA H, MONAHAN KD, SEALS DR: Age-predicted maximal heart rate revisited. J Am Coll Cardiol 37: 153$156,2001$.

VAN BEAUMONT W: Evaluation of hemoconcentration from hematocrit measurements. J Appl Physiol 32: 712-713, 1972.

WALKER AE, KAPLON RE, PIERCE GL, NOWLAN MJ, SEALS DR: Prevention of age-related endothelial dysfunction by habitual aerobic exercise in healthy humans: possible role of nuclear factor $\kappa$ B. Clin Sci (Lond) 127: 645-654, 2014.

WASSERMAN K, HANSEN JE, SUE DY, STRINGER WW, WHIPP BJ: Principles of Exercise Testing and Interpretation, $4^{\text {th }}$ edn. Lippincott Williams and Wilkins, Philadelphia, 2005.

ZOLADZ JA, RADEMAKER AC, SARGEANT AJ: Non-linear relationship between $\mathrm{O}_{2}$ uptake and power output at high intensities of exercise in humans. J Physiol 488: 211-217, 1995.

ZOLADZ JA, MAJERCZAK J, DUDA K, CHLOPICKI S: Exercise-induced prostacyclin release positively correlates with $\mathrm{VO}_{2 \max }$ in young healthy men. Physiol Res 58: 229-238, 2009.

ZOLADZ JA, MAJERCZAK J, DUDA K, CHLOPICKI S: Endurance training increases exercise-induced prostacyclin release in young, healthy men-relationship with $\mathrm{VO}_{2 \max }$. Pharmacol Rep 62: 494-502, 2010.

ZOLADZ JA, MAJERCZAK J, DUDA K, CHLOPICKI S: Coronary and muscle blood flow during physical exercise in humans; heterogenic alliance. Pharmacol Rep 67: 719-727, 2015. 